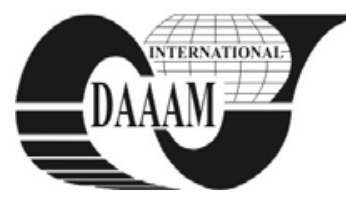

\title{
OVERVOLTAGE LIMIT LIMITER AND LINEAR GALVANIC SEPARATION CIRCUIT IDENTIFICATION AND SIMULATION
}

\author{
OTAHAL, J[iri]; BRAZDIL, M[ichal] \& HRUSKA, F[rantisek]
}

\begin{abstract}
This article describes static and dynamic identification of overvoltage limit limitation circuit and galvanic separation circuit and their simulation in Matlab Simulink development tool. Their static and dynamic properties are described. Created library serves for simulation of nonlinearity embedded to useful input signals.

The research work was performed with financial support of grant reg. No IGA/32/FAI/11/D and by the European Regional Development Fund under the project CEBIA-Tech No.CZ.1.05/2.1.00/03.0089.

Key words: Matlab Simulink, voltage limit limiters, galvanic separation
\end{abstract}

\section{INTRODUCTION}

The use of protective or regulative circuits on input signal changes the signal of actual circuits. If the measured level of voltage has to be precise, it is necessary to know the error that these circuits add to the useful signal. If the signal is dynamic it is necessary to know the dynamic behavior of these circuits.

This article describes two chosen circuits, their static and dynamic behaviors that are simulated and their models in the Matlab Simulink environment are compared to the real circuit data measurements.

\section{STATIC INPUT / OUTPUT CHARACTERISTICS MEASUREMENT}

Static input / output characteristics measurement is a helpful method for finding the static characteristics like gain and saturation voltage of these two circuits. The next reason is the verification of linearity and behavior of the circuits. Measurements were carried out using the equipment described in the next paragraph and a custom measuring program written in VEE Pro 9.0. The input voltage was chosen in the range from $-6 \mathrm{~V}$ to $5.1 \mathrm{~V}$. Step input voltage was $10 \mathrm{mV}$. The waiting time between samples was chosen as $0.2 \mathrm{~s}$ which was sufficient to fully stabilize the input voltage. The supply voltage of both of the power supply circuits IL300 was set to $5.01 \mathrm{~V}$. Measurements were repeated 10 times for each input voltage from $0 \mathrm{~V}$ to $5 \mathrm{~V}$. The circuit with the TL431 was set to limit voltage $2.95 \mathrm{~V}$.

\subsection{Equipment used for static input / output characteristics measurement}

The used measuring equipment:

- Programmable input voltage source Agilent 3632E

- Multimeters Agilent 34410A to measure the output voltage

Multimeters Agilent 34410A were connected to a computer via USB. Agilent E3632A Programmable source was connected to a computer via GPIB and GPIB / USB converter.

\section{CIRCUIT INPUT/OUTPUT WITH TL431 STATIC IDENTIFICATION AND SIMULATION}

The circuit with programmable voltage reference LM431 was experimentally created for behaving as an ideal zener diode. Saturation voltage was set to $2.9 \mathrm{~V}$.

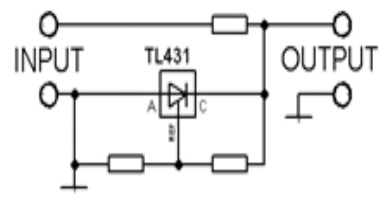

Fig. 1. Circuit with the voltage reference TL431

3.1 Identified equation of static characteristics:

Output train was divided into four intervals and the regression analysis was used to find the equations describing the circuit output train.

$\left(;-5>y=0,0305 x-0,6636 ; R^{2}=0,9879\right.$

$\left(-5 ; 0>y=0,0008 x^{6}+0,0172 x^{5}+0,1413 x^{4}+0,5843 x^{3}+\right.$ $1,2802 x^{2}+1,4652 x+0,0239 ; R^{2}=0,9976$

$\left(0 ; 2,9318>\mathrm{y}=0,9839 \mathrm{x}+0,005 ; \mathrm{R}^{2}=1\right.$

$\left(2,9318 ;>y=0,0021 x+2,9318 ; R^{2}=0,9996\right.$

\subsection{Simulation in Matlab Simulink}

The static characteristic equations have been integrated to the circuit model represented by Embeded Matlab Function block.

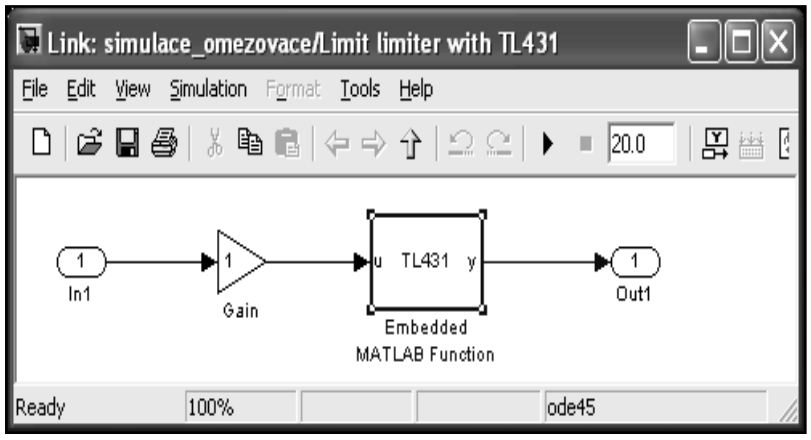

Fig. 2. The circuit with TL431 internal model connection

Static simulation in the Matlab was done and therefore the curve strictly imitates the output signal from the circuit with the TL431 as can be seen in Fig. 3. 


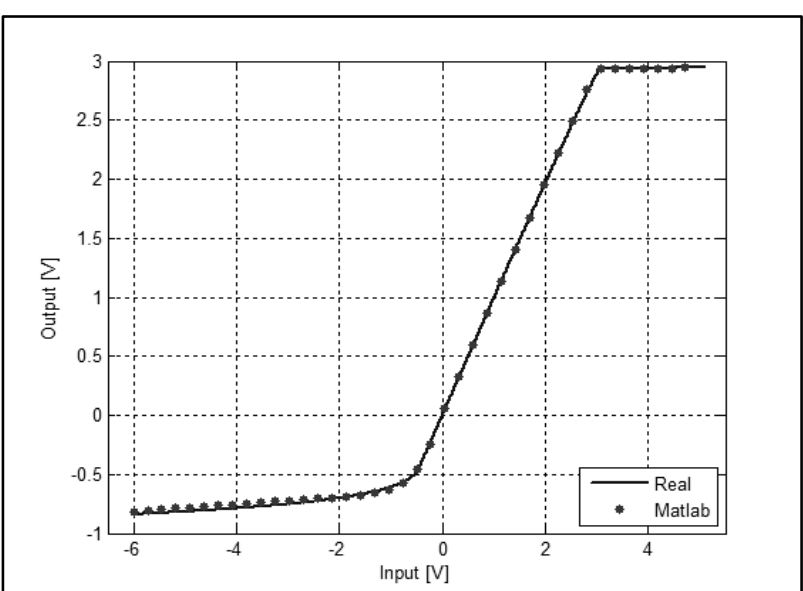

Fig. 3. Circuit with TL431 measured data and Matlab simulation trains comparison

\section{CIRCUIT WITH IL300 STATIC INPUT/OUTPUT IDENTIFICATION AND SIMULATION}

The test module was created. For the circuit with the linear optocoupler IL300 connection the same schematic as in the datasheet for IL300 was used. The input/output characteristic had some deviations. The resulting deviation from the input voltage is determined by the increased gain of operational amplifiers, which can be removed by altering the appropriate circuit connection. $R_{3}$ was set from $30 \mathrm{k} \Omega$ to $21 \mathrm{k} \Omega$. The same oscillation on the same amplitude and frequency is also present when the DC invariable input was used. The oscillation frequency was $178.6 \mathrm{kHz}$ and the amplitude was $1.49 \mathrm{~V}$. When $1 \mathrm{nF}$ capacitor was added to the operational amplifier negative feedback input and the ground, the oscillation was removed. After this modification the circuit output is strictly linear.

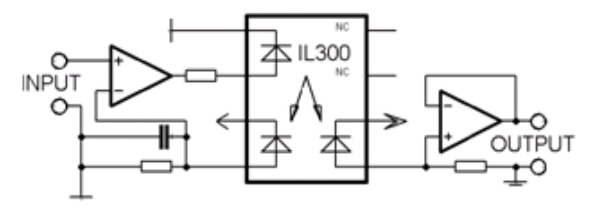

Fig. 4. Circuit with the optocoupler IL300

\subsection{Identified equation of static characteristic}

Output train was divided into three intervals and the regression analysis was used to find the equations describing the circuit output train.

$$
\left(-5 ; 0>\mathrm{y}=0 ; \mathrm{R}^{2}=1\right.
$$$$
\left(0 ; 2,8121>y=1,0005 x-0,0019 ; R^{2}=1\right.
$$$$
\left(2,8121 ; 5>\mathrm{y}=2,8121 ; \mathrm{R}^{2}=1\right.
$$

\subsection{Identified equation of dynamic characteristic}

The Strejc identification method was used for dynamic identification. Since $\tau<0.1$, thereby the transfer function with the different time constants was chosen. Resulting transfer function of the circuit with IL300 is included to a model circuit with linear optocoupler IL300.

\subsection{Simulation in Matlab Simulink}

The static characteristic equations have been integrated to the circuit model, which is represented by Embeded Matlab Function block.

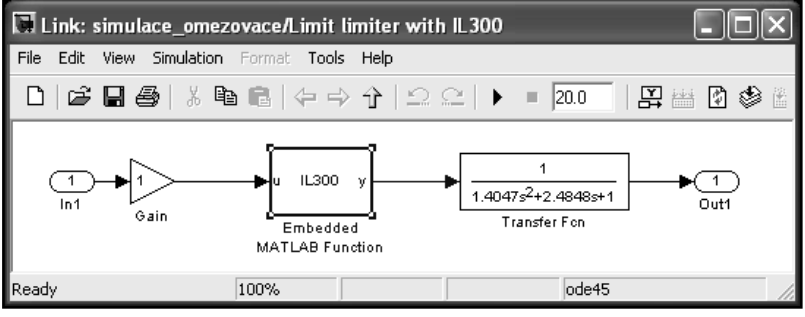

Fig. 5. The circuit with IL300 internal model connection

Static simulation in Matlab was done and therefore the curve strictly imitates the output signal from the circuit with the IL300 as can be seen in Fig. 6.

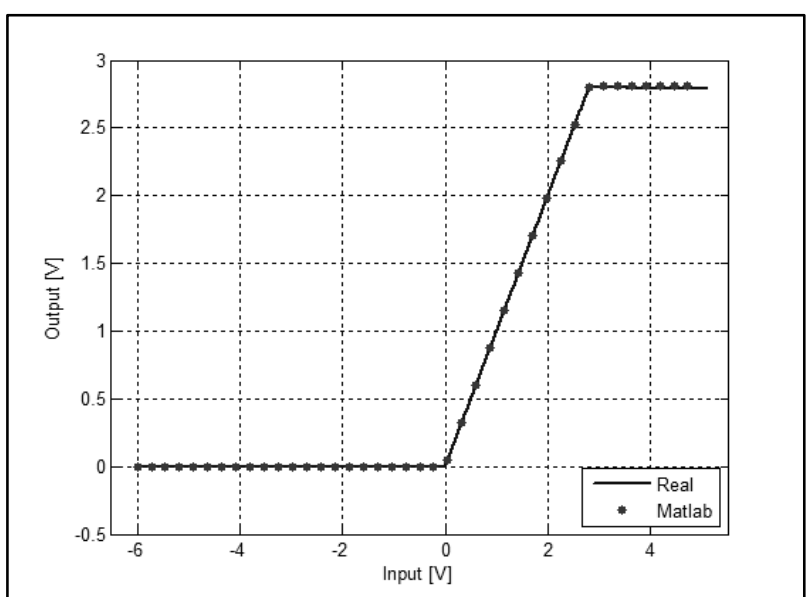

Fig. 6. Circuit with IL300 measured data and Matlab simulation trains comparison

\section{CONCLUSION}

For the measurement of static input/output characteristics a program in VEE 9.0 PRO was created. Principles for the finding of dynamic characteristics of other protections of inputs and outputs were described and demonstrated on the found circuit with IL300 behavior and mathematical description. Circuit models and Matlab Simulink library were created for an easy use of these blocks.

Another part of the work in the next time period is a measurement of parasitic capacitance and inductance.

\section{ACKNOWLEDGEMENTS}

This paper is supported by the Internal Grant Agency at Tomas Bata University in Zlin, project No. IGA/32/FAI/11/D and by the EuropeanRegional Development Fund under the project CEBIA-Tech No.CZ.1.05/2.1.00/03.0089.

\section{REFERENCES}

Tumanski, S. (2006). Principles of electrical measurement. Taylor\&Francis Group, ISBN 0-7503-1038-3

Corriou, J. (2004). Process control: Theory and applications. Springler, ISBN 1852337761, USA

Otáhal, J, et al. (2011). Protections of embedded systems inputs. In OTÁHAL, Jiří. Proceedings of 13th WSEAS International Conference on AUTOMATIC CONTROL, MODELLING \& SIMULATION (ACMOS '11). Otáhal J. (Ed.), pp. 407-411.

STMicroelectronics. (1998). Datasheet IL300

STMicroelectronics. (1998). Datasheet TL431

Balátě, J. (2003). Automatické rízení.: BEN, ISBN 8073000202, Praha, Czech Republic 